\title{
MODERN METHODS TO DETERMINE VITAMIN E IN FOODS AND FEEDS
}

\author{
Bara Camelia ${ }^{1}$, Bara Lucian¹, Bara Vasile ${ }^{1}$, Burta Ligia $^{2}$, Domuta Cristian ${ }^{1}$ \\ ${ }^{1}$ University of Oradea - Faculty of Environmental Protection, 26 General Magheru str., Oradea \\ ${ }^{2}$ University of Oradea - Faculty of Medicine and Pharmacy
}

Key words:. tocopherol, food, feed, fluorometry

\begin{abstract}
Summary
Highly specific and sensitive, the proposed fluorometric method for determining $\alpha$-tocopherol is robust and fairly fast. It has been tested in parallel with a conventional thin layer chromatographic method on foods and feeds. The only necessary cleanup is the usual saponification. The unsaponificable fraction can be extracted with ethyl ether or, preferably, with Extrelut columns. Reagents and their solvents are added to the isooctane solution before each successive reaction and are then eliminated by partition with water. The $\alpha$-tocopherol $(\alpha-T)$ derivative always remains in isooctane. The first step is nitrosation and elimination of tocopherols and tocotrienols other than $\alpha$-isomers. $\alpha-T$ is then oxidized to $\alpha$-tocored ( $\alpha$-TR) with a mixture of sulfuric acid, ferric chloride, and iodine bromide. A-TR is then condensed to a new reagent: 4,5-dimethylo-phenylenediamine. The phenazine formed is strongly fluorescent. Iodine and bromine add to the double bonds of $\alpha$ tocotrienol present and quench the fluorescence of its phenazine.
\end{abstract}

\section{INTRODUCTION}

The determination of vitamin $\mathrm{E}$ in food or feedstuffs poses a difficult problem. Eight natural homologs possess a vitamin activity: 4 tocopherols and 4 tocotrienols. Among them, $\alpha$-T is by far the most active compound. It is generally agreed that $\alpha-\mathrm{T}$ accounts for about $80 \%$ of vitamin E supply in foods. Moreover, it is the only homolog used in modern feeding. The other homologs have lower activities and it is difficult if not impossible to determine them all. In practice, only $\alpha$-T is routinley determined. But the other homologs, as well as various substances, interfere in the determination of $\alpha-\mathrm{T}$.

Conventional methods for determination of $\alpha-T$ are lengthy, not specific, and not precise. To separate interfering substances, a tedious cleanup of the sample is necessary. This is usually done by column or thin layer chromatography, and it is still necessary to undertake special treatments before chromatography, such as cleanup with Floridin or sulfuric acid treatment (1,2). Methods using gas chromatography (GC) necessitate a sophisticated cleanup which renders GC almost unnecessary (3). Recently, liquid chromatography (LC) has been proposed. It is more satisfactory than conventional methods, including GC (4). Yet the analysis of complex mixtures containing low levels of $\alpha$-T and high levels of interfering substances may pose problems. Even with a fluorescence detector, the risk of interference is not negligible. For routine analysis, column pollution may be a severe drawback. Although LC is faster than conventional methods, the separation of $\alpha-\mathrm{T}$ in complex mixtures such as foods and feeds require $20 \mathrm{~min}$ or more. This is inherent in the technique, to make sure there is no interference due to a compound retained on the column, it is necessary to carry out 2 determinations, which expands further the time required. Finally, the LC technique requires expensive equipment and solvents.

These considerations led us to develop a method based on the succession of several specific reactions, which needs no special cleanup, and which can be automated according to the continuous flow technique.

\section{METHOD}

\section{Apparatus}

(a) Glassware.- Round-bottom flasks, volumetric flasks, and separatory funnels, all low-actinic glass.

(b) Heating baths.-With precise temperature regulation $\left(+-1^{\circ} \mathrm{C}\right)$.

(c) Rotary evaporator.-

(d) Spectrofluorometer. Wavelengths for maximum are ca $382 \mathrm{~mm}$ (excitation) and $495 \mathrm{~mm}$ (emission), but these values depend on instrument used. (We chose 370 and $500 \mathrm{~mm}$ to avoid a Raman peak.) Slitwidth: $10 \mathrm{~nm}$ (excitation) and 5 $\mathrm{nm}$ (emission). Expansion 20. Calibrate fluorometer at $90 \%$ fluorescence with quinine sulfate standard solution, at $348 \mathrm{~nm}$ (excitation) and $448 \mathrm{~nm}$ (emission). Check these wavelengths when operating another instrument.

(e) Filter fluorometer.-Alternatively, use simple filter fluorometer instead of spectrofluorometer, but filters must be adequately chosen. For filter fluorometer used in automated method choose following filters: primary filter, interferential filter with maximum transmission at $366 \mathrm{~nm}(345$ to $390 \mathrm{~nm})$ (ca $25 \%$ transmission); secondary filter: 50 broad-band interferential filter with maximum transmission at $500 \mathrm{~nm}(460-540 \mathrm{~nm})$ (ca $75 \%$ transmission).

\section{Reagents and Solutions}

(a) Ethanol.-Absolute

(b) Potassium hydroxide solution.-Dissolve $200 \mathrm{~g} \mathrm{KOH} \mathrm{(86 \% )} \mathrm{in} 1 \mathrm{~L}$ water.

(c) All-rac- $\alpha$-tocopherol stock solution. $-80 \mathrm{mg} / 200 \mathrm{~mL}$ ethanol. Store $<=1$ month at $-18^{\circ} \mathrm{C}$. 
(d) All-rac- $\alpha$-tocopherol working solutions.-Starting from solution (c), prepare daily dilutions $(2,4,6 \mu \mathrm{g} / \mathrm{mL})$ with ethanol.

(e) Sodium nitrite solution.-Dissolve $2 \mathrm{~g}$ in $50 \mathrm{~mL}$ water, then add $50 \mathrm{~mL}$ ethanol. Store in refrigerator $<=1$ week.

(f) Iodine bromide solution $1.2 \%(\mathrm{w} / \mathrm{v})$ in ethanol (a). Store at $-18^{\circ} \mathrm{C}<=1$ month.

(g) Ferric chloride stock solution. $-70 \%$ (w/v) $\mathrm{FeCl}_{3} 6 \mathrm{H}_{2} \mathrm{O}$ in ethanol (a). Store $<=1$ month at room temperature.

(h) Oxidizing solution.-In $500 \mathrm{~mL}$ volumetric flask containing ca $300 \mathrm{~mL}$ ethanol (a), add successively $10.0 \mathrm{~mL}$ $\mathrm{FeCl}_{3}$ solution (g), $10.0 \mathrm{~mL}$ Ibr solution (f), and $10.0 \mathrm{~mL} 98 \% \mathrm{H}_{2} \mathrm{SO}_{4}$. Adjust to volume with ethanol (a). Prepare daily.

(i) DMPD solution.-1\% (w/v) 4,5-dimethyl-o-phenylenediamine (Aldrich) in 100\% acetic acid. Prepare daily.

(j) Buffer solution.-Prepare aqueous $15 \%(\mathrm{w} / \mathrm{v}) \mathrm{NaH}_{2} \mathrm{PO}_{4} \mathrm{H}_{2} \mathrm{O}$ solution and adjust $\mathrm{pH}$ to 5.5 with potassium hydroxide (b).

(k) Quinine sulfate stock solution. $-100 \mathrm{mg} / 500 \mathrm{~mL} 0.1 \mathrm{~N}$ sulfuric acid. Store $<=1$ month in refrigerator. refrigerator.

(l) Quinine sulfate working solution.- Dilute solution (k) to $0.04 \mu \mathrm{g} / \mathrm{mL}$ with $0.1 \mathrm{~N}$ sulfuric acid. Store $<=1$ week in

(m) Hydrophobic folded filters.

\section{Reagents for Sample Preparation}

(a) Pyrogallol solution.-Dissolve $0.1 \mathrm{~g}$ pyrogallol in $4 \mathrm{~mL}$ water, add $20 \mathrm{~mL}$ ethanol, and adjust volume to $100 \mathrm{~mL}$ with methanol.

(b) Potassium hydroxide solution.-Dissolve $700 \mathrm{~g} \mathrm{KOH}(86 \%)$ in $600 \mathrm{~mL}$ water and adjust volume to $1 \mathrm{~L}$.

(c) Ethyl ether.-Free of peroxides. Or, instead, Extrelut columns and fillings

(d) Ascorbic Acid.-Aqueous solution, 20\% (w/v).

\section{Sample Preparation (Saponification and Extraction)}

A) Foods.-Weigh $10 \mathrm{~g}$ sample in $250 \mathrm{~mL}$ low-actinic flask, add $50 \mathrm{~mL}$ pyrogallol solution (a), add $10 \mathrm{~mL} \mathrm{KOH}$ solution (b), and heat with reflux under nitrogen for $20 \mathrm{~min}$. Shake flask from time to time, or preferably, use magnetic stirrer. When saponification is ended, rinse cooler with a few $\mathrm{mL}$ water and transfer the whole contents to separatory funnel with help of $50 \mathrm{~mL}$ water.

Rinse empty flask with $120 \mathrm{~mL}$ ethyl ether (c), transfer rinse to separatory funnel, and extract unsaponifiable matter. Extract twice again with $120 \mathrm{~mL}$ ethyl ether. Collect ether phases and wash 3 times with $100 \mathrm{~mL}$ water. The last water phase must be neutral. Take aliquot from ether solution, add a few $\mathrm{mL}$ ethanol (a), and evaporate at $50{ }^{\circ} \mathrm{C}$ under vacuum. Dissolve residue in ethanol (a).

B) Feeds.-Saponification A can be employed, but procedure B is preferable in most cases. Weigh $50 \mathrm{~g}$ sample in $1 \mathrm{~L}$ lowactinic flask. Add $400 \mathrm{~mL}$ pyrogallol solution (a) and add $80 \mathrm{~mL} \mathrm{KOH}$ solution (b). Weigh flask and heat with reflux for 20 min under nitrogen. Shake flask from time to time or, preferably, use magnetic stirrer. Rinse condenser with $20 \mathrm{~mL}$ water and weigh flask again. Bring weigh to its initial value plus $20 \mathrm{~g}$ with a few $\mathrm{mL}$ ethanol (a) if necessary. Take $100 \mathrm{~mL}$ aliquot and transfer to separatory funnel. Add $50 \mathrm{~mL}$ water and $120 \mathrm{~mL}$ ethyl ether (c) and continue extraction as in A. Advantages of procedure B are a higher sample weight, and absence of solid particles during extraction. Disadvantages are that the $100 \mathrm{~mL}$ aliquot must be representative of the whole solution (usually it is), and that feeds contain some water not considered. When the water content is $<10 \%$, then the error is negligible $(<2 \%)$. If the water is $>10 \%$, then it should be taken into account in the calculation.

C) Oils and fats.-Weigh $5 \mathrm{~g}$ oil in $250 \mathrm{~mL}$ low-actinic flask. Add $100 \mathrm{~mL}$ pyrogallol solution (a), add $15 \mathrm{~mL} \mathrm{KOH}$ solution (b), and heat with reflux for 20 min under nitrogen. Shake flask from time to time or, preferably, use magnetic stirrer. Rinse condenser with a few $\mathrm{mL}$ water and transfer contents to separatory funnel with the help of $50 \mathrm{~mL}$ water. Add $120 \mathrm{~mL}$ ethyl ether (c) and continue as in procedure A.

Note: Heating of saponification solution lasts $20 \mathrm{~min}$, starting from the beginning of reflux.

Substitution of Extrelut columns for ether extractions.-Ethyl ether is dangerous and onerous to use. The 3 extractions of unsaponifiable material followed by 3 washings are time consuming. Use of purification columns requires much less time, is as effective, and is more selective (blanks are reduced) (5).

Instead of transferring saponification solution to separatory funnel, pippet $40.0 \mathrm{~mL}$ aliquot into $50 \mathrm{~mL}$ volumetric flask and adjust to volume with ascorbic acid solution (d). Shake, and transfer $20.0 \mathrm{~mL}$ of this solution to Extrelut column. Wait $15 \mathrm{~min}$ after application, set $50 \mathrm{~mL}$ volumetric flask under column and elute with $60 \mathrm{~mL}$ isooctane. Collect $40 \mathrm{~mL}$ during elution $=>25 \mathrm{~min}$. Keep flask in freezer $\left(-18^{\circ} \mathrm{C}\right)$ and adjust to volume with isooctane just before determination. If automated system is used, then isooctane solution is directly passed into automated system. If manual system is used (this article), then an aliquot of the isooctane solution containing 40-120 $\mu \mathrm{g} \alpha-\mathrm{T}$ is evaporated, and residue is dissolved in $20.0 \mathrm{~mL}$ ethanol (a). Analytical Procedure

Operate in subdued light. Dilute ethanolic solution of $\alpha$-T to concentration between 2 and $6 \mu \mathrm{g} / \mathrm{mL}$.

Nitrosation.-Pour $20.0 \mathrm{~mL}$ ethanolic solution inti $250 \mathrm{~mL}$ separatory funnel. Add $0.6 \mathrm{~mL} 100 \%$ acetic acid, then $9 \mathrm{~mL}$ sodium nitrite (e). Stir, and wait exactly $2 \mathrm{~min}$. Add $6 \mathrm{~mL}$ potassium hydroxide (b) and stir. Add $20 \mathrm{~mL}$ isooctane, shake 1 min, and let phases separate. Discard bottom phase and wash upper phase with $20 \mathrm{~mL}$ buffer solution (j). After separation, filter upper phase through hydrophobic filter $(\mathrm{m})$ into $100 \mathrm{~mL}$ round-bottom flask. Rinse separator and filter with $10 \mathrm{~mL}$ 
isooctane.

Oxidation to $\alpha$-TR.-Add $30 \mathrm{~mL}$ oxidizing solution (h), set flask in heating bath at $50{ }^{\circ} \mathrm{C}$ with cooler, and wait 30 min. Quantitatively transfer contents to $250 \mathrm{~mL}$ separatory funnel with help of $30 \mathrm{~mL}$ water. Shake 1 min, let phases separate, discard bottom phase, and wash upper phase with $30 \mathrm{~mL}$ buffer solution (j); separate and filter organic phase through hydrophobic filter $(\mathrm{m})$ into $250 \mathrm{~mL}$ round-bottom flask. Rinse separator and filter with $10 \mathrm{~mL}$ isooctane.

Reaction of $\alpha$-TR with DMPD.-Add $40 \mathrm{~mL}$ DMPD solution (i). Set flask in heating bath at $90{ }^{\circ} \mathrm{C}$ with cooler (not under nitrogen) and wait $30 \mathrm{~min}$. Cool rapidly and transfer contents to $250 \mathrm{~mL}$ separatory funnel. Wash flask with $40 \mathrm{~mL} 16 \% \mathrm{Hcl}$ and rinse to separatory funnel, shake $1 \mathrm{~min}$, and let phases separate. Wash upper phase twice with $40 \mathrm{~mL}$ buffer solution (j). Filter organic phase through hydrophobic filter $(\mathrm{m})$ into $50 \mathrm{~mL}$ volumetric flask. Rinse separator and filter with $10 \mathrm{~mL}$ isooctane. Bring volume to $50 \mathrm{~mL}$ with isooctane. If fluorometry is performed the next day, keep solution in refrigerator $(+$ $4{ }^{\circ} \mathrm{C}$ ). Before measurement, pipet $10.0 \mathrm{~mL}$ isooctane solution, add $10.0 \mathrm{~mL}$ ethanol (a), and stir.

Fluorometry

Calibrate fluorometer at $90 \%$ fluorescence with quinine sulfate working solution (l) and perform fluorescence measurement. Blank assay $\left(\mathrm{H}_{2} \mathrm{O}\right.$ ).-Only the oxidation (to $\alpha$-TR) step is changed: Add $30 \mathrm{~mL}$ oxidizing solution (h), then add $1.0 \mathrm{~mL}$ water and set flask in heating bath at $50{ }^{\circ} \mathrm{C}$. Let stand $2 \mathrm{~min}$, and stir to obtain one phase. Then wait $28 \mathrm{~min}$, and transfer to 250 $\mathrm{mL}$ separatory funnel...(as in normal assay procedure).

Calibration line.-Carry out 2 determinations according to above procedure with each $\alpha$-T standard working solution (d). Check reagent blank (normal procedure with all reagents but no $\alpha-T$ ). Usually it is equal 3-4 \%. Subtract water blank assays from values obtained foe each point and plot fluorescence intensity concentration.

Calculation.-For each sample assay, subtract water blank from normal assay value and calculate $\alpha$-T concentration with help of calibration line.

Operating notes: (1) If irregular results occur, then make sure that glassware is clean (in particular, pipets). (2) Oxidation of $\alpha$-T to $\alpha$-TR is sensitive to water. Absolute ethanol used to prepare solution (h) usually contains $0.1 \%$ water. This content varies somewhat, so it is preferable to use the same batch for calibration curve and samples. When determinations are carried out during the whole day, it is better to separate the oxidizing solution (h) in 2 parts (for morning and afternoon). Make sure that glassware used to carry out this reaction is dry. (3) Fluorescence measurements must be performed at approximately the same temperature. Use a thermostatically controlled cell holder if temperature varies too much.

\section{RESULTS}

\section{Statistical Evaluation}

Twelve calibration lines were carried out with standard ethanolic $\alpha$-T solutions of concentrations $0,2,4,6 \mu \mathrm{g} / \mathrm{mL}$. The $r^{2}$ value of the calibration line was 0.998 , and the coefficients of variation (CV) were as follows: $0 \mu \mathrm{g} / \mathrm{mL}, 4.8 \% ; 2$ $\mu \mathrm{g} / \mathrm{mL}, 3.2 \% ; 4 \mu \mathrm{g} / \mathrm{mL}, 3.5 \% ; 6 \mu \mathrm{g} / \mathrm{mL}, 1.5 \%$. The mean $\mathrm{CV}$ of the 3 concentrations $2,4,6 \mu \mathrm{g} / \mathrm{mL}$ was $2.7 \%$.

The CV obtained with a $6 \mu \mathrm{g} / \mathrm{mL} \alpha$-T standard solution (highest point of calibration line) over a one month period was $2.8 \%$ (70 determinations).

\section{Selectivity}

To check the selectivity of the proposed method, we have run normal determinations and related blank assays with several compounds whose structures are similar to that of $\alpha-T$, or which are likely to interfere. The results are given in Table 1. As can be seen, no one interferes, even at concentrations one hundred times that of $\alpha$-T. The $\beta$-, $\gamma$-, and $\delta$ - tocopherols, as well as $\alpha$-tocotrienol, also do not interfere.

\section{Assays of Foods and Feeds}

To test the proposed method, we ran parallel determinations with our former method. We have been using this latter method for about 10 years, although it was published only recently (2).

(a) Principle of TLC method (2).-After saponification, the unsaponifiablematter is cleaned on a silica gel chromatography column, the $\alpha$-T zone is collected and submitted to a sulfuric acid treatment, then $\alpha$-T is isolated by silica gel thin layer chromatography (TLC). After desorption, it is quantitated with the Emmerie-Engel technique.

(b) Comparison between methods.-The samples were sapinified according to the TLC method and aliquots of the unsaponifiable matter were determined by both methods. Two determinations were carried out with each method, blank assays were done with the proposed method. The results are given in Table 2.

It is interesting to note that results agreed well, even for soyabean oil which contains between 5 and $10 \% \alpha$-T relative to the sum of the tocopherols (this vegetable oil contains the lowest ratio of $\alpha$-T). Moreover, the value found for the blank was very high ( $43 \%$ of the total fluorescence), yet there was no quenching due to blank impurities.

Table 1. Assay of compound which might interferre in fluorometric assay of $\alpha$-tocopherol 


\begin{tabular}{|c|c|c|c|}
\hline \multirow[t]{2}{*}{ Compound } & \multicolumn{2}{|c|}{ Concn, ${ }^{\mathrm{a}}$ Fluorescence, ${ }^{\mathrm{b}}$} & \multirow{2}{*}{$\begin{array}{c}\text { Blank, } \\
\%\end{array}$} \\
\hline & $\mu \mathrm{g} / \mathrm{mL}$ ethanol & $\%$ & \\
\hline$\alpha-\mathrm{T}$ & 6 & 70 & 3.1 \\
\hline$\beta-\mathrm{T}^{\mathrm{c}}$ & 6 & 2 & 0 \\
\hline$\gamma-T^{d}$ & 6 & 6.5 & 6.5 \\
\hline$\delta-\mathrm{T}$ & 6 & 0 & 0 \\
\hline$\alpha-\mathrm{T}^{\mathrm{d}}$ & 6 & 3 & 3 \\
\hline BHA & 600 & 2 & 0 \\
\hline $\mathrm{BHT}$ & 12000 & 0 & 0 \\
\hline Ethoxyquin & 600 & 1.5 & 0.5 \\
\hline 1,2-Dihydroxy naphthalene & 600 & 0 & 0 \\
\hline Naphthalene-1,2-quinone & 12000 & 0 & 0 \\
\hline Pyrocatechol & 600 & 0 & 0 \\
\hline Pyrocatechol monoethyl ether & 600 & 1.5 & 0.5 \\
\hline Pyrocatechol monomethyl ether & 600 & 0 & 0 \\
\hline 3,4-Dimethylphenol & 12000 & 1 & 1 \\
\hline Pyrogallol-1-methyl ether & 12000 & 0 & 0 \\
\hline
\end{tabular}

${ }^{a}$ Concentrations are given for the initial ethanolic solutions.

${ }^{\mathrm{b}}$ The reagent blank has been subtracted.

${ }^{c}$ The fluorescence obtained is likely an artifact, since we had difficulties isolating it from a antural extract.

${ }^{\mathrm{d}}$ Values found are due to impurities.

\section{Recovery}

The recovery factor of $\alpha$-T measured in several foods and feeds. The samples were first assayed for $\alpha$-T. Then known amounts of $\alpha$-T $(60 \mu \mathrm{g})$ were added to the initial $20 \mathrm{~mL}$ ethanolic solutions of the samples. All the determinations were carried out only once. As can be seen in Table 3, the obtained differences were closed to the expected ones (92-110\%) with an average of $100.2 \%$.

Extraction of the unsaponifiable matter on Extrelut cartridges gave similar results to the usual ethyl ether extraction.

\section{DISCUSSION}

In the first step, saponification, one must make sure that the amount of sample weighed is representative of the product to be analyzed. This depends on the concentration. A general rule is to weigh not less than $10 \mathrm{~g}$ supplemented feedstuffs. Usually we weigh $50 \mathrm{~g}$.

It is important to mention that saponification, besides its usual actions, destroys $\alpha$-tocopherolquinone $(\alpha$-TQ) and $\alpha$-tocored $(\alpha$-TR) if present in the sample.

Table 2. Comparison of proposed method and conventional TLC method for $\alpha$-tocopherol

\begin{tabular}{llll} 
& \multicolumn{2}{c}{ Proposed method } & TLC method \\
\cline { 2 - 4 } & Fample & Blank, $\%$ & $\mathrm{mg} / 100 \mathrm{~g}$
\end{tabular}

\begin{tabular}{llllll}
\hline Croquettes for cats & 50.5 & 11.5 & 17.1 & 16.8 & +2.2 \\
Sunflower oil & 45.5 & 6.0 & 74.6 & 73.1 & +2.0 \\
Infant milk & 51.6 & 13.0 & 11.1 & 11.1 & 0 \\
Mineral premix 1 & 87.8 & 5.8 & 2661 & 2786 & -4.5 \\
Mineral premix 2 & 30.0 & 8.9 & 7569 & 7679 & -1.4 \\
Pet food (for cats) & 12.2 & 5.0 & 2.15 & 2.0 & +7.5 \\
Corn seed & 57.0 & 10.1 & 19.9 & 20.4 & -2.3 \\
Spreading paste & 47.6 & 5.0 & 10.1 & 10.4 & -2.6 \\
Soyabean oil & 37.9 & 16.2 & 14.3 & 14.6 & -2.4 \\
\hline
\end{tabular}


The nitrosation reaction is done according to Quaife (6), to eliminate the homologs of $\alpha$-T and the phenolic impurities. A-T does not undergo nitrosation because it has no free aromatic site, but it does not remain unchanged: It undergoes a fast esterification with nitrous acid to form the nitrite ester.

We have found no mention of this reaction in the literature. It might be related to the ability of $\alpha$-T to prevent the formation of nitrosamines. Fortunately, the nitrous ester is oxidized as rapidly as the free form of $\alpha$-T and also gives $\alpha$-TR. Furter and Meyer (7) carried out the oxidation with concentrated nitric acid $(65 \%)$ in ethanolic solution. We had difficulties using $65 \% \mathrm{HNO}_{3}$. The reaction was erratic. Results were even less reproducible with very dilute $\alpha$-T solutions, as we tried to increase the sensitivity of the method.

We decided to look for another reagent, but the usual oxidizing agents of $\alpha$-T, such as ferric chloride and ceric sulfate, yield other derivatives, such as the para-quinone ( $\alpha$-TQ), instead of the ortho-quinone ( $\alpha$-TR) (8). Sulfuric acid is able to produce only limited amounts of $\alpha$-TR and the reaction is irregular.

Table 3. Recovery factors of proposed manual method
Food/feed ${ }^{\mathrm{a}}$
$\alpha$-T content, mg/100g
Recovery factor, \%

Cattle vitamin premix

Pig vitamin premix

Cattle mineral premix

Turkey mineral premix

Chicken feed

Chicken feed ${ }^{b}$

Cattle feed

Cattle feed ${ }^{\mathrm{b}}$

Chick feed

Chick feed ${ }^{\mathrm{b}}$

Corn seeds soup

Dietetic corn seeds ${ }^{\mathrm{b}}$

Dietetic corn seeds

Pig feed

Pig feed ${ }^{\mathrm{b}}$

Cocoa breakfast ${ }^{\mathrm{b}}$

Cocoa breakfast

Dietetic food
$830 \quad 101$

$420 \quad 102$

$16.7 \quad 101$

100

$1.95 \quad 94$

$1.95 \quad 93$

$2.1 \quad 95$

$2.1 \quad 105$

4.497

4.4104

$2.5 \quad 92$

$2.13 \quad 106$

$2.13 \quad 106$

$2.44 \quad 110$

$2.44 \quad 102$

$2.5 \quad 101$

$2.5 \quad 102$

? 99

Average $=\quad 100.22$

${ }^{\mathrm{a}}$ Unsaponifiable extraction with ethyl ether.

${ }^{\mathrm{b}}$ Unsaponifiable extraction with Extrelut cartridges.

\section{CONCLUSIONS}

We finally found that a mixture of sulfuric acid, ferric chloride, and iodine bromide, dissolved in ethanol in given proportions, is able to form $\alpha$-TR. Although the yield is somewhat lower than with $\mathrm{HNO}_{3}($ about 50-60\%), the results are reproducible because the amount of formed $\alpha$-TR reaches a plateau. The reaction is carried out in isooctane amd ethanol (isooctane being present at every step, since it is the carrier solvent). Alcohol is necessary for the reaction to proceed.

Simultaneous use of the 3 oxidizing agents is necessary. We tried iodine bromide because we wanted to quench the fluorescence of the phenazines formed by the tocotrienols and especially $\alpha$-tocotrienol $(\alpha-\mathrm{T} 3)$. These compounds are homologs of $\alpha-T$ in which the side chain, instead of being saturated, contains 3 double bonds. They have a low biological activity and frequently occur in feedstuffs, where they interfere in the determination of $\alpha$-T. It is well known that heavy atoms (such as iodine or bromine) when bound to a molecule quench its fluorescence. Iodine bromide is able to add such atoms to the double bonds and it quenches the fluorescence. To save time, the reaction between tocotrienols and iodine bromide was done simultaneously with the formation of $\alpha$-TR. By chance, the latter reaction was facilitated by iodine bromide.

We found that formation of $\alpha$-TR is blocked when a small amount of water (3.3\%) is added to the ethanolic solvent. But water does not block the oxidation of 1,2-dihydroxy-aromatic impurities. For example, pyrocatechol reacts with ferric chloride in presence or absence of water in the same way. $\alpha$-T is first oxidized to $\alpha$-tocopherolquinone ( $\alpha$-TQ) (in presence or absence of water), then $\alpha$-TQ is oxidized and converted by sulfuric acid to $\alpha$-TR. This second step is very sensitive to 
water. With $3.3 \%$ water, the inhibition is $96 \%$ effective, so only $4 \%$ of the fluorescence is due to the phenazine. When the water blank gives a higher value than $4 \%$ (after subtraction of the reagent blank), then the difference is due to a fluorescent impurity. The possibility of quenching is reduced because the $\alpha$-T solutions measured are very dilute (vide infra).

We substituted 4,5-dimethyl-o-phenylenediamine (DMPD) for OPD. The obtained derivative is likely to be a phenazine too. The reaction rate in the fluorescence intensity are much higher with DMPD. Kofler used acetic acid as solvent, and we used a mixture of acetic acid and isooctane (the latter as carrier). After the phenazine is formed, excess DMPD is extracted with hydrochloric acid. The acetic acid also passes into the aqueous phase.

The isooctane phase contains the phenazine, which fluoresces only after addition of ethanol. The excitation maximum occurs at $382 \mathrm{~nm}$ and the emission at $495 \mathrm{~nm}$. These wavelengths are rather remote from the ususal range of fluorescence. To avoid a Raman peak at $437 \mathrm{~nm}$, it is preferable to use $370 / 500 \mathrm{~nm}$ instead of $382 / 495 \mathrm{~nm}$.

The results obtained with the method are reliable and the precision is satisfactory $(\mathrm{CV}=2.8 \%)$. Ethanolic $\alpha$-T solutions with concentrations as low as $2 \mu \mathrm{g} / \mathrm{mL}$ can be assayed, so the method can be used for most food and feedstuffs.

\section{REFERENCES:}

1. Cahoon EB (2005) "Metabolic Engineering of Crop Plants for Improved Human Nutritional and Livestock Feed Value". Molecular and Cell Biology Department, Uniformed Services University of the Health Sciences, Bethesda, MD. Invited seminar, April 15, 2005.

2. Cahoon EB (2005) "Toward the Biofortification of Food and Feed: Characterization of the Biosynthesis of Vitamin K and the Tocotrienol Form of Vitamin E'. Department of Crop Science, University of Illinois, Urbana-Champaign, IL. Invited seminar September 14, 2005.

3. Cahoon, E.B. (2005) "Toward the Biofortification of Food and Feed: Characterization of the Biosynthesis of Vitamin K and the Tocotrienol Form of Vitamin E". Department of Chemistry and Chemical Biology, Indiana University-Purdue University-Indianapolis. Indianapolis, IN. Invited seminar, November 30, 2005.

4. Cahoon, E.B. (2006) "Metabolic Engineering of Antioxidant and Unusual Fatty Acid Biosynthesis in Crop Plants for Improved Nutritional, Livestock Feed, and Industrial Value”. Plant Science Initiative, University of Nebraska-Lincoln, Lincoln, NE. Invited seminar, June 21 , 2006.

5. Cahoon, E.B. (2006) "Metabolic Redesign of Vitamin E Biosynthesis in Soybean Seeds for Increased Antioxidant Content". Soy2006: Molecular and Cellular Biology of the Soybean Conference, Lincoln, NE. Meeting presentation, August 7, 2006.

6. Cahoon, E.B. (2006) "Toward the Biofortification of Food and Feed: Characterization of the Biosynthesis of Vitamin K and the Tocotrienol Form of Vitamin E”. Plant Sciences, University of Missouri-Columbia, Columbia, MO. Invited seminar, February 15, 2006.

7. Cahoon, E.B. (2007) "Characterization of Tocotrienol Biosynthesis for the Metabolic Engineering of Oilseeds with Improved Antioxidant Capacity". First International Symposium on Secondary Metabolism in Plant Seeds: Current Status and Future Applications, Potsdam, Germany. Meeting presentation, February 17, 2007.

8. Cahoon, E.B. (2007) "Metabolic Redesign of Vitamin E Biosynthesis in Soybean Seeds for Increased Antioxidant Content". Crop Science Society of America Annual Meeting, New Orleans, LA. Meeting presentation, November 6, 2007

9. Cahoon, E.B. (2007) "Understanding the Biosynthesis of the Tocotrienol Form of Vitamin E for the Biofortification of Crops". Phytochemical Society of North America Annual Meeting, Saint Louis, MO. Meeting presentation, July 22, 2007.

10. D.I. Sanchez-Machado, J. Lopez-Cervantes,N.J. Rios Vazquez,: High-performance liquid chromatography method to measure $\alpha$-and $\gamma$ tocopherol in leaves, flowers and fresh beans from Moringa oleifera, Journal of Chromatography A.,2006, 1105, $111-114$.

11. E. Ryan, K. Galvin, T.P.O'Connor,A.R.Maguire, N.M. O’Brien,: Phytosterol,Squalene, Tocopherol content and fatty acidprofile of selected seeds, grains, and legumes,Plant Foods Hum Nutr., 2007, 62:85-91.

12. I.G. Zigoneanu, L.Williams, Z. Xu, C.M.Sabliov, Determination of antioxidant components in rice bran oil extracted by microwaveassistedmethod, Bioresource Technology, 2008, 99: 4910-4918;

13. J. Lopez-Cervantes, D.I. Sanchez-Machado,N.J. Rios Vazquez,: Journal of ChromatographyA., 2006,1105: 135-139;

14. Maziar Mohiti Asli, Seyed AbdollahHosseini, Houshang Lotfollahian and FaridShariatmadari,: Effect of probiotics, yeast,vitamin E and vitamin C supplements onlperformance and immune response of laying henhigh environmental temperature, InternationalJournal of Poultry Science., 2007, 6 (12); $895-900$.

15. Ordinul ANSVSA nr.51/2005 pentruaprobarea Normei sanitar veterinare deimplementare a masurilor de supraveghere sicontrol al unor substante si al reziduurilor acestorala animale vii si la produsele lor privindperformanta metodelor analitice si interpretarearezultatelor.

16. Robert Gianello, Roksan Libinaki, AngeloAzzi, Paul D.Gavin, Yesim Negis, Jean-MarcZingg, Phillip Holt, Hooi-Hong Keah, AnnikeGriffey, Andrew Smallridge, Simon M.West, EsraOgru, A,: Tocopheryl phosphate: A novel, naturalform of vitamin E, Free RadicalBiology\&Medicine, 2005, 39: 970-976.

17. Shipp, J.M., Hunter, S.C., Cahoon, E.B. (2006) "Vitamin E and Pro-Vitamin A Biofortification of Soybean". National Center for Soybean Biotechnology Second Annual Symposium. Columbia, MO. Meeting presentation, March 22, 2006.

18. Standardul SE EN ISO/CEI 17025:2005,Cerinte generale pentru competenta laboratoarelor de incercari si etalonari;

19. Standardul SR EN ISO 6867:2001, Nutreturi-Determinarea continutului de vitamina E-Metodaprin cromatografie de lichide de inaltaperformanta.

20. Stephane Castan, Claude Villard, StefanJakob, Antoine Puigserver, El Hassan Ajandouz,A,: fast, sensitive method for the simultaneousdetermination of alfa-tocopherol and alphatocopherylacetate in mixed micelles, Journal ofChromatography B., 2005, 822:339-346.

21. Svetlana A. Lanina, Patricia Toledo, SabineSampels, Afaf Kamal-Eldin, Jelena A. Jastrebova, Comparison of reversed- phase liquidchromatography-mass spectrometry withelectrospray and atmosferic pressure chemicalionization for analysis of dietary tocopherols,Journal of Chromatography A., 2007, 1157:159-170;

22. Tanase and col, 2007,: Validation analytical methods.

23. $\quad * * *$ Eurachem, 2003, The fitness for purposeof analytical methods. A Laboratory Guide tolMethod Validation and Related Topics

24. $\quad * * * I C H$ Q2B, 1996, Analytical Validation-Methodology. 